Javanmardi, A., Abbasian-Hosseini, S. A., Hsiang, S.M., and Liu, M. (2018). "Constraint Removal and Work Plan Reliability: A Bridge Project Case Study." In: Proc. 26 th Annual Conference of the International. Group for Lean Construction (IGLC), González, V.A. (ed.), Chennai, India, pp. 807-817. DOI: doi.org/10.24928/2018/0510.Available at: www.iglc.net

\title{
CONSTRAINT REMOVAL AND WORK PLAN RELIABILITY: A BRIDGE PROJECT CASE STUDY
}

\author{
Ashtad Javanmardi ${ }^{1}$, S. Alireza Abbasian-Hosseini ${ }^{2}$, Simon M. Hsiang ${ }^{3}$, \\ and Min Liu ${ }^{4}$
}

\begin{abstract}
Effective removal of constraints is critical in the Last Planner System (LPS $\left.{ }^{\circledR}\right)$ to improve work plan reliability. While removing constraints is important, it remains unclear to project managers about which types of constraint have the highest level of uncertainty and to what extent the constraint removal discussions are efficient for improving work plan reliability. This research uses a bridge project as an example to answer these research questions. The authors collected planning meeting minutes, look ahead plans, and production dataof 11 weeks to analyze constraint removal discussions in weekly plan meetings and the associated Percent Plan Complete (PPC).Information theory method was used to calculate the amount of information gain and the information transmission efficiency for PPC improvement.

Results show that "Prerequisite Readiness" is the most important constraint to discuss and contributes to $24 \%$ of the total information gain for PPC improvement. This constraint also has the highest information transmission efficiency of $36 \%$, almost twice the average information transmission efficiency of the other constraints. The method proposed in this paper can be used repetitively on other projects and will help project managers to improve their meeting effectiveness in order to achieve higher work plan reliability.
\end{abstract}

\section{KEYWORDS}

Meeting, information theory, plan reliability, constraint analysis, lean construction

1 Ph.D. Candidate, Dept. of Civil Const. and Envir. Eng., North Carolina State Univ., Raleigh, NC 27695-7908, USA, +1 919 987-5010, ajavanm@ncsu.edu

2 Research Associate, Dept. of Civil Const. and Envir. Eng., North Carolina State Univ., Raleigh, NC 27695-7908, USA, +1 919 917-4547, sabbasi@ncsu.edu

3 Professor, Dept. of Syst. Eng.and Eng. Mgmt., Department Chair, Univ. of North Carolina at Charlotte, Charlotte, NC 28223-0001, USA, +1 704687-1958, shsiang1@ uncc.edu

4 Associate Professor, Dept. of Civil Const. and Envir. Eng., North Carolina State Univ., Raleigh, NC 27695-7908, USA, +1919513-7920, min_liu@ ncsu.edu 


\section{INTRODUCTION}

Last Planner System $\left(\right.$ LPS $\left.^{\circledR}\right)$ is a pull-driven production scheduling method developed to improve plan reliability and productivity for construction projects (Ballard 2000). Instead of emphasizing on deadlines, LPS ${ }^{\circledR}$ emphasizes on constraint removal in the make-ready process to produce high reliable short-term work plans (Hamzeh et al. 2015). According to Koskela (1999)there are seven constraints that shouldbe removed for having sound assignments. These constraints are: 1) external conditions (i.e. weather), 2) equipment availability, 3) labor availability, 4) material availability, 5) prerequisite work readiness, 6) space availability, and 7) design and working method clarification.

Project managers hold planning meetings to identify constraints, discuss ways to remove constraints, and provide updates on the status of constraint removal. Several studies addressed this process (Jang and Kim 2008; Lind hard and Wandahl 2012; Hamzehet al. 2015; Wang et al. 2016). According to the authors' knowledge, limited research wasfound to quantify the information gain and transmission of constraint removal and how it affects work plan reliability.

To fill in this gap of knowledge, this research aims to 1) quantify the information gain for each constraint removal, 2) measure the information transmission efficiency of constraint removal discussion in planning meetings, and 3) propose a guideline to improve the meeting effectiveness in order to increase plan reliability. This research collected planning and production data from a bridge project and used the information theory framework to analyze the data. The results are useful for project managers by providing a better understanding the impacts of constraint removal on planning reliability.

\section{LITERATURE REVIEW}

\section{LPS ${ }^{\circledR}$ AND CONSTRAINT REMOVAL}

LPS $^{\circledR}$ is a production planning and control system based on lean production principles that aims to improve the reliability of work plans (Ballard 2000).LPS ${ }^{\circledR}$ uses Percent Plan Complete (PPC) as an indicator forplan reliability. PPC is calculated by dividing the number oftasks completed $100 \%$ at the end of a plan period(i.e. a week) relative to those tasks planned at the beginning of that plan period.(Liu et al. 2010; Hamzeh et al. 2015).LPS ${ }^{\circledR}$ improves PPC by ensuring only sound activities are selected for execution in the short-term period (Lindhard and Wandahl2012). Sound activities refer to the activities which their constraints are completely removed (Koskela 1999).

Koskela (1999) specified seven internal and external constraints that can interrupt smooth execution of activities. By focusing on three residential and educational case studies and analyzing about 1280 reasons for task non-completion, Lindhard and Wandahl (2012) found the seven Koskela's constraints (Koskela 1999) plus two additional constraints namely unsafe working conditions and unknown working conditions were underlying reasons for non-completed tasks. Jang and Kim (2008) showed that there is a significant positive relationship between Percentage of Constraint Removal (PCR) and PPC by collecting data from two bridge construction projects. In a more recent study, through computer simulation and using Tasks Made Ready (TMR) 
measurement, Hamzehet al. (2015) showed identifying and eliminating constraints during make-ready process influence the reliability of construction lookahead plans and impact project duration. Previous research emphasized the importance of constraint removal. But they did not investigate the information gain and transmission of constraint removal information during weekly planning meetings and how it impacts PPC.

\section{INFORMATION THEORY}

In construction, information can be communicated in different formats using different verbal and non-verbal methods. Scholars in Civil Engineering have used information theory to find best schemes for optimal communication of information. Jalayer et al. (2012) compared several alternative Intensity Measures (IMs) in terms of the expected difference in the information provided about a predicted structural drift response and the most informative of those IMs identified. To identify the important factors affecting the constructability, Chang et al. (2017) utilized information theory to quantify the amount of information needed to construct truss structural systems with different assembly.

Although there has been limited use of information theory in Civil Engineering, to the best of the authors' knowledge, none of the researchers utilized information theory in analyzing construction meetings.Information theory has some distinctive abilities to 1)measure the amount of information;2) estimate the amount of information gain;and 3)quantify the efficiency of information transmission.

To measure the amount of information a variable generates, this research calculates entropy, $H(X)$, introduced by Shannon (1948), using the following equation:

$$
H(X)=\sum_{i=1}^{m} p\left(x_{i}\right) \log _{2} \frac{1}{p\left(x_{i}\right)} \text { bits }
$$

In Eq. $1, X$ is a discrete random variable which can take $m$ possible outcomes of $x_{i}$, where $p\left(x_{i}\right)$ is the probability for the random variable $X$ to have the outcome $x_{i}, x_{i} \in\left\{x_{1}\right.$, $\left.x_{2}, \ldots, x_{m}\right\}$.The unit of information in Eq. 1is bit. One bit represents the amount of information required for one of two equally probable alternatives to be specified(Stone, 2015).Entropy is the amount of information that can be conveyed by the random variable(Stone, 2015).

To estimate the amount of information gained about one variable giving another, this research calculates mutual information, $I(X, Y)$, using following equation (Shannon 1948):

$$
I(X, Y)=\sum_{i=1}^{m_{x}} \sum_{j=1}^{m_{y}} p\left(x_{i}, y_{j}\right) \log _{2} \frac{p\left(x_{i}, y_{j}\right)}{p\left(x_{i}\right) p\left(y_{j}\right)} \text { bits }
$$

In Eq. 2. $X$ and $Y$ are two discrete random variables that can take $m_{x}$ and $m_{y}$ possible different values respectively. $p\left(y_{j}\right)$ is the probability for the random variable $Y$ to have the outcome $y_{j}$ and $p\left(x_{i}, y_{i}\right)$ is the joint probability for $X$ and $Y$. Mutual information can be calculated by Eq. 3 . 


$$
I(X, Y)=H(X)+H(Y)-H(X, Y) \text { bits }
$$

where

$$
H(X, Y)=\sum_{i=1}^{m_{x}} \sum_{j=1}^{m_{y}} p\left(x_{i}, y_{j}\right) \log _{2} \frac{1}{p\left(x_{i}, y_{j}\right)} \text { bits }
$$

is the joint entropy between $X$ and $Y$. Mutual information is a general measure of association between two variables and measures how much knowing one of these variables reduces uncertainty about the other(Stone, 2015).

To quantify the efficiency of information transmission between variables, information transmission efficiency can be calculated using the following equation:

$$
\text { Information Transmission Efficiency }=\frac{I(X, Y)}{H(X)}
$$

Where $H(X)$ is the amount of information about uncertainty that variable $X$ generates, and $I(X, Y)$ is the amount of information gained about $Y$ given $X$.

\section{METHOD}

Figure 1 shows research design for this paper. First two sets of data, weekly planning meeting minutes and weekly lookahead plan, were collected from the case study project. Meeting minutes were studied and categorized to identify the frequency of discussion regarding each of the constraint removals during meetings. Lookahead plan and consequence were used to calculate PPC. Once PPC values were calculated, they were divided into three groups low, medium, and high using $k$-means clustering algorithm. Next, information gain and information transmission efficiency were calculated for every constraint category. Finally, the paper proposed a plan for improvement of meeting effectiveness to achieve higher PPC.

\section{CASE DESCRIPTION}

A bridge construction project was selected for this study because it contained linear and repetitive activities which are comparable in terms of work complexity across the project. The project was a Design-Build project with an estimated cost of $\$ 200$ million. The project started in March 2016 and it was scheduled to get completed in September 2019. The project was over 90\% self-performed by the General Contractor (GC) who had highly-trained and experienced labors in addition to specialized equipment required for this project. Therefore, GC team was directly responsible for planning, and managing labor, materials and equipment throughout the duration of the studied phase.

The scope of this study is the pile installation activity of three bents lasted for 11 weeks. Bents are the supporting structures for the bridge's girders and decks and are consisted of two main substructure, piles and caps. Each bent had three $140 \mathrm{ft}$ cylinder concrete piles needed to be driven approximately $110 \mathrm{ft}$ into the ground. The pile 
installation activity was performed by a crew of six people, including one foreman, four workers, and one crane operator who were managed by GC's personnel.

The project did not use LPS ${ }^{\circledR}$ as the method of scheduling and control system, but they practiced some elements of LPS ${ }^{\circledR}$ unintentionally. For example, the project had three weeks lookahead plans which were updated weekly after weekly planning meetings. Plans in this project were created and updated by the project control team after receiving feedback from superintendents and field engineers and there was no systematic procedure for removal of constraints before adding tasks to weekly work plans.

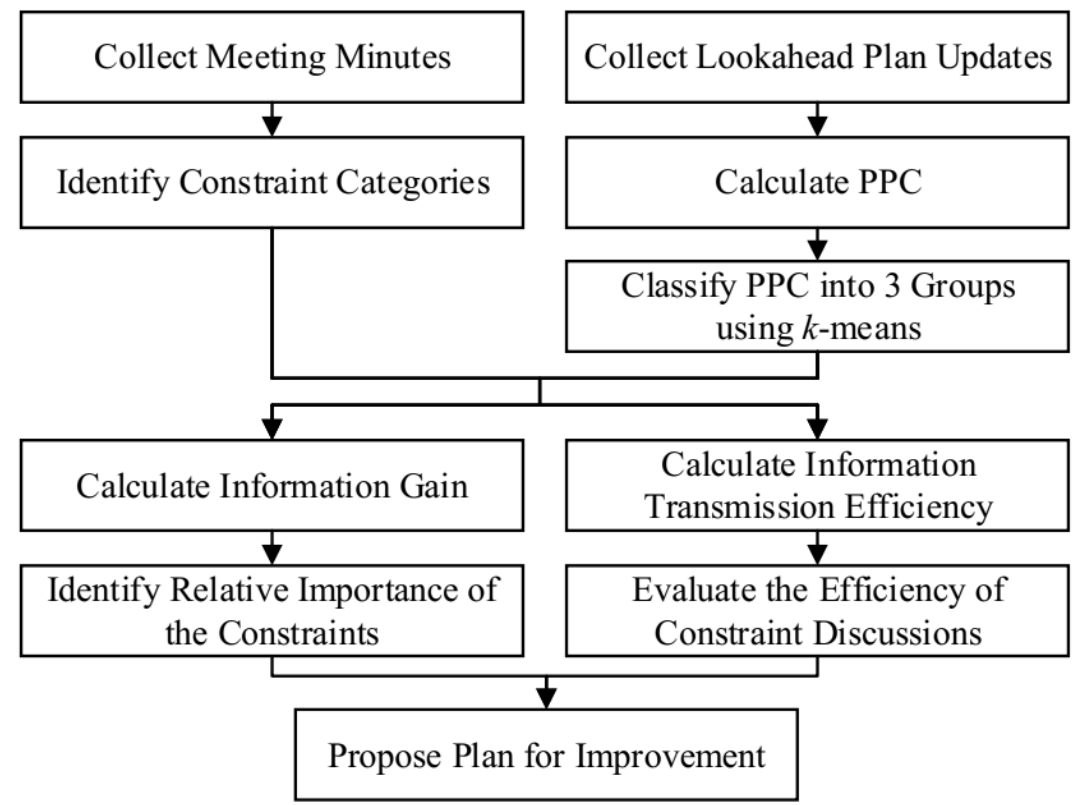

Figure 1: Flowchart for Research Method

\section{Weekly Planning Meetings}

In this project meetings were held every Wednesday at 4PM. The average meeting duration was 108 minutes with a minimum of 86 minutes and a maximum of 135 minutes. The number of meeting participants ranges from 7 to 15, with an average of 11 . Participants include one to three construction and project managers, one project control manager, one to two general superintendents, one to three crew superintendents, one to three project engineers, and three to five field engineers. Meetings were facilitated/chaired by the project manager. In these meetings, participants discussed pile installation activity as well as other major activities, such as trestle installation, cap installation, girder installation, deck installation. There were also discussions regarding project general condition and other matters (i.e. safety, contract documents, site layout, etc.). For this study, the authors consider only the portion of the meetings that is relevant to pile installation activities.

Meeting minutes were descriptive and contained what transpired during the meetings. All the 11 minutes were taken by the same project engineer who had7 years of construction experience and had participated in all the meetings on the project from the 
first day. After carefully reviewing the meeting minutes, the authors classified the discussion items for pile installation activity into the seven constraint categories mentioned by Koskela (1999).It should be noted that the validity of identifying constraint categories based on the minute notes was checked by the GC's pile installation field engineer who participated in all the 11 meetings and was fully aware of the context behind the minutes.

\section{PPC CALCULATION AND CLASSIFICATION}

Lookahead plans in this project were updated every Friday, demonstrating the actual start times and actual finish times of pile installation activities in the current week and the week before. In addition, lookahead plans contained the planned start times and the planned finish times of pile installation activities of the future three weeks.

This study uses PPC as the measure of plan reliability and can be calculated as follow (Liu et al. 2010):

$$
\text { PPC }=\frac{\text { Number of completed tasks out of the planned tasks }}{\text { Total number of planned tasks }}
$$

To differentiate between plan reliabilities, $K$-means clustering algorithm (Ibbs and Liu 2011) and SAS Enterprise Miner (SAS EM) 14.2 were used to classify PPC. SAS EM provides user friendly interface where building models require simple clicks and drag and drop nodes into the diagram area. $K$-means tries to classify PPCs into $K$ clusters ( $K$ is defined by the user) in which each PPC belongs to the cluster with the nearest mean. The reason for selecting $K$-means for clustering was that its algorithm is a non-overlapping algorithm and PPCs will not be classified to more than one cluster.

\section{INFORMATION GAIN AND INFORMATION TRANSMISSION EFFICIENCY}

This study took the following steps to calculate entropy and information gain for constraint discussion:

1. Categorize meetings based on the seven constraints and record the frequency of constraint removal discussions into variables $X_{1}$ to $X_{7}$ where $X_{1}=$ External Conditions, $\mathrm{X}_{2}=$ Equipment Availability, $\mathrm{X}_{3}=$ Labor Availability, $\mathrm{X}_{4}=$ Material Availability, $\mathrm{X}_{5}=$ Prerequisite Work Readiness, $\mathrm{X}_{6}=$ Space Availability, and $\mathrm{X}_{7}=$ Design and Working Method Clarification. (Table 1, columns 2-8). Also, classify PPCs into L, M or H and record data into a discrete variable Y (Table 1, column 9-10).

2. Generate a Cross-tab between every $\mathrm{X}$ and Y.Every cross-tab displays the distribution of the $\mathrm{X}$ variable against the $\mathrm{Y}$ variable in the 2-dimensional matrix format. The rows in cross-tabs are the frequencies of constraint removal discussion in meetings (i.e.once, twice, three times, etc.) and the columns are PPC levels (i.e. L, M or H).

3. Add a row and a column to the created cross-tabs in theprevious stepand insert the sum of rows and columns of the cross-tabs generated in step 2.

4. Calculate joint and marginal probabilities by dividing every cell of cross-tabs in step 3 by the total sum.

5. Take the logarithms to the base 2 of the inverse probabilities in step 4 . 
6. Calculate joint and marginal entropies using Eq. 4.

7. Calculate every $\mathrm{X}$ and $\mathrm{Y}$ entropies using Eq. 1. and summing marginal entropies calculated in step 6.

8. Calculate the mutual information using Eq. 3 based on the results of steps 6 and 7 .

9. Calculate information transmission efficiency using Eq.5 based on the results in steps 7 and 8.

Table 1: Constraint Removal Discussion and PPC Categorization

\begin{tabular}{|c|c|c|c|c|c|c|c|c|c|}
\hline $\begin{array}{c}\text { Week } \\
\text { (1) }\end{array}$ & $\begin{array}{c}\text { External } \\
\text { Conditions } \\
\text { (2) }\end{array}$ & $\begin{array}{c}\text { Equipment } \\
\text { Availability } \\
\text { (3) }\end{array}$ & $\begin{array}{c}\text { Labor } \\
\text { Availability } \\
\text { (4) }\end{array}$ & $\begin{array}{c}\text { Material } \\
\text { Availability } \\
\text { (5) }\end{array}$ & $\begin{array}{c}\text { Prerequisite } \\
\text { Readiness } \\
\text { (6) }\end{array}$ & $\begin{array}{c}\text { Space } \\
\text { Adequacy } \\
\text { (7) }\end{array}$ & $\begin{array}{l}\text { Design } \\
\text { and } \\
\text { Method } \\
\text { (8) }\end{array}$ & $\begin{array}{c}\text { PPC } \\
(9)\end{array}$ & $\begin{array}{c}\text { PPC } \\
\text { Categories } \\
(10)\end{array}$ \\
\hline 1 & 0 & $\overline{0}$ & 2 & 0 & $\overline{0}$ & 0 & 1 & $0 \%$ & $\mathrm{~L}$ \\
\hline 2 & 0 & 0 & 2 & 0 & 0 & 0 & 0 & $0 \%$ & $\mathrm{~L}$ \\
\hline 3 & 0 & 1 & 0 & 0 & 0 & 0 & 3 & $0 \%$ & $\mathrm{~L}$ \\
\hline 4 & 0 & 0 & 1 & 0 & 0 & 0 & 1 & $13 \%$ & $\mathrm{~L}$ \\
\hline 5 & 0 & 1 & 1 & 0 & 0 & 0 & 1 & $43 \%$ & $\mathrm{M}$ \\
\hline 6 & 1 & 1 & 1 & 2 & 0 & 1 & 2 & $5 \%$ & $\mathrm{~L}$ \\
\hline 7 & 0 & 0 & 1 & 2 & 2 & 0 & 3 & $45 \%$ & $\mathrm{M}$ \\
\hline 8 & 0 & 0 & 2 & 2 & 0 & 0 & 2 & $22 \%$ & $\mathrm{M}$ \\
\hline 9 & 0 & 0 & 1 & 0 & 2 & 0 & 3 & $0 \%$ & $\mathrm{~L}$ \\
\hline 10 & 0 & 1 & 0 & 2 & 2 & 0 & 3 & $67 \%$ & $\mathrm{H}$ \\
\hline 11 & 1 & 1 & 2 & 0 & 2 & 0 & 2 & $67 \%$ & $\mathrm{H}$ \\
\hline
\end{tabular}

\section{RESULT AND DISCUSSION}

In Table $2, H(X)$ represents the amount of information generated by constraint categories. $H(Y)$ represents the uncertainty in PPC or the amount of information needed to eliminate uncertainty in PPC. Uncertainty arisesfrom the unpredictability of next week's PPC, whether it is going to be $\mathrm{L}, \mathrm{M}$, or $\mathrm{H} . \mathrm{I}(X, Y)$ is the amount of information gained about PPC given the constraint information. $I(X, Y) / H(X)$ is the information transmission efficiency between constraints and PPC. For example, the amount of information "Design and Working Method Clarification $\mathrm{X}_{7}$ "generated is 1.87 bits, almost twice the information that "Prerequisite Work Readiness $\mathrm{X}_{5}$ "generated, which is 0.95 bits. Comparing between the two aforementioned constraint categories, information gained from the latter one is $0.34 / 0.21=1.62$ times more than the information gained from the former one. The information transmission efficiency for $\mathrm{X}_{5}$ is almost three times more than information transmission efficiency for $\mathrm{X}_{7}$ (0.36 vs. 0.11$)$.

Table 2: Information Gained and Transmission Efficiency in Weekly Meetings

\begin{tabular}{ccccc}
\hline Constraints & $\mathrm{H}(\mathrm{X})$ & $\mathrm{H}(\mathrm{Y})$ & $\mathrm{I}(\mathrm{X}, \mathrm{Y})$ & $\mathrm{I}(\mathrm{X}, \mathrm{Y}) / \mathrm{H}(\mathrm{X})$ \\
\hline $\mathrm{X}_{1}$ & 0.68 & 1.44 & 0.15 & 0.22 \\
$\mathrm{X}_{2}$ & 0.99 & 1.44 & 0.24 & 0.24 \\
\hline
\end{tabular}




\begin{tabular}{lllll}
\hline $\mathrm{X}_{3}$ & 1.49 & 1.44 & 0.27 & 0.18 \\
$\mathrm{X}_{4}$ & 0.95 & 1.44 & 0.16 & 0.17 \\
$\mathrm{X}_{5}$ & 0.95 & 1.44 & 0.34 & 0.36 \\
$\mathrm{X}_{6}$ & 0.44 & 1.44 & 0.08 & 0.19 \\
$\mathrm{X}_{7}$ & 1.87 & 1.44 & 0.21 & 0.11 \\
\hline
\end{tabular}

In Table 2 all numbers are in the units of a bitexcept the last column. Table 2 shows there are 1.44 bits of uncertainty in the PPC. As a result, 1.44 bits of information should be gained to eliminate the uncertainty. The total information that can be gained from the

constraint removal discussions is

$$
\sum I(X, Y)=1.45 \text { bits }
$$
amount of uncertainty in PPC.

which is almost equal to the

Figure 2 shows the risk of missing constraint removalinformation calculated by dividing the information gain from each constraint by the total information gained. The top three categories that highly contribute to the total information gain for PPC improvement are "Prerequisite Work Readiness". "Labor Availability", and "Equipment Availability."

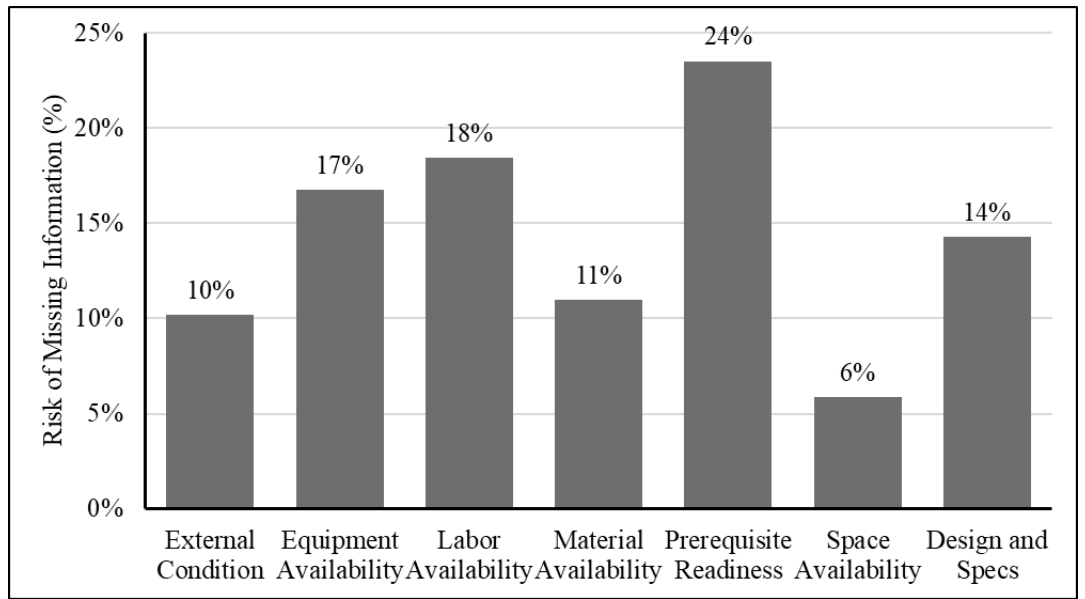

Figure 2: Risk of missing constraint removal category information

In Figure 3,the $\mathrm{X}$-axis is information gain and theY-axis is information transmission efficiency. The chart is divided further into four areas based on the average information gain and average information transmission efficiency of all constraints. Figure 3 shows that "Design and Working Method Clarification $\left(\mathrm{X}_{5}\right)$ )" discussion not only result in high information gain, but also the information is transmitted in high efficiency of $36 \%$. 


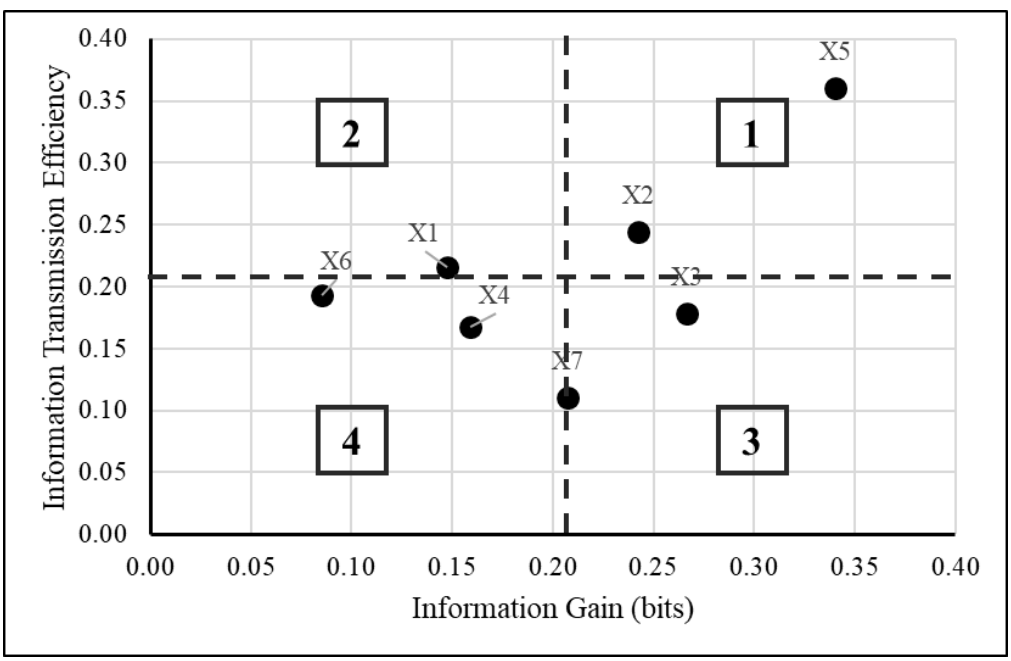

Figure 3: Information Gained vs. Information Transmission Efficiency

Figure 3 provides a basis for prioritizing constraint removal discussion in weekly meetings. In the $1^{\text {st }}$ area of Figure 3, constraints are both important for PPC improvement and were efficiently discussed. Therefore, constraints in this area $\left(\mathrm{X}_{5}\right.$ and $\left.\mathrm{X}_{2}\right)$ have the highest priority for discussion at meetings. In the $2^{\text {nd }}$ area of Figure 3 , constraints were less important for PPC improvement, but they were efficiently discussed. Therefore, constraints in this area $\left(\mathrm{X}_{1}\right)$ were addressed concisely with less effort and have second priority for discussion at meetings. In the $3^{\text {rd }}$ area of Figure 3 , constraints were important for PPC improvement, but they were not efficiently discussed. Therefore, constraints in this area $\left(\mathrm{X}_{3}\right.$ and $\left.\mathrm{X}_{7}\right)$ took more effort to be addressed and have third priority for discussion. Finally, in the $4^{\text {th }}$ area of Figure 3, constraints were less important for PPC improvement and were not discussed efficiently. Therefore, constraints in this area $\left(\mathrm{X}_{4}\right.$ and $\mathrm{X}_{6}$ ) have the lowest priority for discussion at meetings. Prioritizing constraint discussion in this way will assure that more information for PPC improvement is gained in a limited time (meeting duration).

\section{CONCLUSIONS}

Using information theory and based on a case study, this paper showed how project managers can improve their effectiveness of weekly meetings by prioritizing the list of meeting agenda and ensuring that the most important constraints get removed. The findings of this paper showed weekly planning meetings work best to solve issues related to sequencing, whereas other types of meetings are maybe required for more technical matters.Results in Figure 2 can be translated to expected PPC improvements by multiplying the numbers in Figure 2 by $64 \%(64 \%$ is the PPC improvement from the $\mathrm{L}$ category with the average PPC of $3 \%$, to the $\mathrm{H}$ category with the average PPC of $67 \%$ in Table 1). For example, the expected PPC improvement by gaining information about "Prerequisite Work Readiness $\left(\mathrm{X}_{5}\right)$ " will be $0.24 \times 0.64=15 \%$.

Figure 3 implied that the quality and effectiveness of communications on a subject were not necessarily derived from the volume of information generated on it. For instance, 
results showed that "Prerequisite Work Readiness $\left(\mathrm{X}_{5}\right)$ " information was communicated almost 3 times more efficiently than information regarding "Design and Working Method Clarification $\left(\mathrm{X}_{7}\right)$ ". Since the pile installation tasks were performed in a sequence and removing any prerequisite work-related constraints was a high priority for the project team. Also, the communications addressing this constraint in weekly meetings usually had a quick and direct impact on the PPC of the following week. In contrast, communications over "Design and Working Method Clarification $\left(\mathrm{X}_{7}\right)$ " were not fully effective because its impacts were not fully reflected in the PPC measured in the following week. For instance, at the beginning of the project, the construction method was to jet the piles to a certain elevation before driving them to the final tip elevation to keep the driving stresses low by lowering the driving length. After installation of a few piles and measuring pile stresses during driving, project team realized there was no need to jet the pile prior driving and they could remove the costly and time-consuming jetting operation from the work plan. The communication over this issue was done over several weeks and in a several meetings (including the weekly progress meeting) and the impact of these communications and decisions is not measurable by the PPC of a particular week and was reflected in a longer period.

The analysis in this paper can be repeated during a project to improve its future meeting effectiveness after enough data has been collected from its past meetings. The authors believe communication about constraints, and the subsequent follow up of these, would be much more effective if constraints were addressed and categorized directly in the work plan during the planning meetings. It should be noted that this paper considered the Koskela's seven constraint categories (Koskela 1999). However, there were some constraints that did not fit into the Koskela's constraints (i.e. unsafe working conditions). Future research can consider a broader range of constraints and include their impacts on schedule performance. In this paper every discussion was fitted into only one constraint base on the content behind the discussion. Future research, however, can fit discussions to multiple constraints and consider information sharing among them and propose more advanced methods for prioritizing constraint removal discussions.

\section{REFERENCES}

Ballard, G. (2000). "The Last Planner System of production control." Ph.D. Diss., Univ. of Birmingham, Birmingham, UK.

Chang, M. C., Shih, S. G., and Schmitt, G. (2017). "Information theory-based approach for constructability assessment in truss structural systems." Auto. Constr., 82, 84-102.

Hamzeh, F. R., Zankoul, E., and Rouhana, C. (2015). "How can 'tasks made ready'during lookahead planning impact reliable workflow and project duration?" Constr. Manage. Econ., 33(4), 243-258.

Ibbs, W. and Liu, M. (2011). "An improved methodology for selecting similar working days for measured mile analysis." Int. J. Proj. Manage., 29(6), 773-780.

Jalayer, F., Beck, J. L., and Zareian, F. (2011). "Analyzing the sufficiency of alternative scalar and vector intensity measures of ground shaking based on information theory." J. Eng. Mech, 138(3), 307-316. 
Jang, J.W. and Kim, Y.W. (2008). "The Relationship Between the Make-Ready Process and Project Schedule Performance" Proc.,16th Ann. Conf. of the Int. Group for Lean Construction, Manchester, UK, 647-656.

Koskela, L. (1999)."Management of production in construction: A theoretical view."Proc.,7thAnn.Conf. of the Int. Group for Lean Construction, University of California, Berkeley, CA,USA, 241-252.

Lindhard, S. and Wandahl, S. (2012)."Improving the Making Ready Process - Exploring the Preconditions to Work Tasks in Construction"Proc., 20th Ann.Conf. of the Int. Group for Lean Construction, San Diego, USA, 451-460.

Liu, M., Ballard, G., and Ibbs, W. (2010). "Work flow variation and labor productivity: Case study.” J. Manage. Eng., 27(4), 236-242.

Shannon, C. E. (1948). "A mathematical theory of communication." Bell Syst. Tech. J., 27(3), 379-423.

Stone, J. V. (2015). Information theory: A tutorial introduction. Sebtel Press.

Wang, J., Shou, W., Wang, X., and Wu, P. (2016). "Developing and evaluating a framework of total constraint management for improving workflow in liquefied natural gas construction." Constr. Manage. Econ.,34(12), 859-874. 